\title{
РОСТ ЗАРОДЫША И ПРОРАСТАНИЕ ГЕТЕРОМОРФНЫХ СЕМЯН Anethum graveolens L. (Apiaceae) ПОД ДЕЙСТВИЕМ ВЫСОКОЙ ТЕМПЕРАТУРЫ
}

\author{
А.В. СОЛДАТЕНКО ${ }^{\circledR}$, А.Ф. БУХАРОВ 1 , Д.Н. БАЛЕЕВ 2 , М.И. ИВАНОВА 1 , \\ П.А. НАЗАРОВ 3 , О.А. РАЗИН1, А.Ф. РАЗИН 1
}

Гетероморфизм широко распространен в природе и проявляется в варьировании различных параметров семян у отдельных особей и в пределах популяции. Для семян укропа (Anethum graveolens L.) характерен гетероморфизм, обусловленный материнским фактором. Он влияет прежде всего на величину семян, при этом может наблюдаться варьирование размеров зародыша. Высокая температура - неблагоприятный абиотический фактор, воздействию которой могут подвергаться растения на разных стадиях развития. В настоящей работе в процессе проращивания интактных семян укропа впервые выявлена значительная термочувствительность зародышей из семян, сформированных в соцветиях второго порядка ветвления, к длительному действию супероптимальной температуры. При воздействии высокой температуры происходило угнетение роста зародышей и, как следствие, прорастания интактных семян укропа, полученных из соцветий второго порядка. Нашей целью было изучить влияние матрикального фактора, а также высокой температуры на рост зародыша и прорастание интактных семян укропа, сформированных в соцветиях разных порядков ветвления. Опыты проводили в 2015-2016 годах во Всероссийском НИИ овощеводства - филиал ФГБНУ Федеральный научный центр овощеводства. Объектом исследований служили семена укропа позднеспелого сорта Кентавр, сформированные в соцветиях первого (1п) и второго (2п) порядков ветвления. Семена получали с растений укропа, выращенных в открытом грунте. Уборку проводили на 50-е сут после цветения зонтиков первого порядка. Эксперименты проводили в термостате с контролируемой температурой. Чтобы определить критическую температуру для роста зародыша при проращивании и прорастании интактных семян, воздействовали широким диапазоном высоких температур: $20{ }^{\circ} \mathrm{C}$ (контроль) - среднеоптимальная температура для семян, не находящихся в состоянии покоя; 25, 30, 35 и $40{ }^{\circ} \mathrm{C}$. Используя морфометрический метод анализа, изучили рост зародыша и динамику прорастания интактных семян. На основании полученных данных строили кривые роста зародыша и прорастания интактных семян. Логистическую регрессию использовали для расчета максимальной сверхоптимальной температуры, при которой возможен рост зародыша и прорастание семян. Показано, что зародыши, сформированные в семенах из зонтиков разных порядков ветвления, находились на разных стадиях развития. Начальные размеры зародышей 1п были на 30 \% больше, чем зародышей 2п (р < 0,001). Зародыши 1п и 2п имели разную термочувствительность при прорастании в стрессовых условиях, но при приближении к критической температуре различия нивелировались. Так, увеличение температуры проращивания до $40{ }^{\circ} \mathrm{C}$ приводило к угнетению роста зародышей и прорастания семян из соцветий как 1п (р < 0,001), так и 2п (р < 0,001). Влияние высоких температур имело решающее значение для роста зародыша $(57 \%, \mathrm{~F}=415,3, \mathrm{p}<0,001)$ и прорастания семян укропа $(37,2 \%, \mathrm{~F}=270,5$, p < 0,001). Максимальная температура, при которой был возможен рост зародышей 1п, составляла $40 \pm 0,4^{\circ} \mathrm{C}, 2 п-38 \pm 0,5^{\circ} \mathrm{C}(\mathrm{p}<0,001)$. Максимальная температура, допускающая проклевывание не менее $50 \%$ жизнеспособных семян 1п $-34 \pm 0,3{ }^{\circ} \mathrm{C}, 2$ п $-30 \pm 0,4{ }^{\circ} \mathrm{C}(\mathrm{p}<0,001)$. Семена были более чувствительны к высоким температурам, чем зародыши. Рост зародыша оказывал значительное влияние на прорастание семян $(r=0,946, t=25,85, \mathrm{p}<0,001)$. Таким образом, термочувствительность зародышей из семян, сформированных в соцветиях второго порядка ветвления, была одной из основных причин медленного, неоднородного и неполного прорастания популяции семян укропа в сверхоптимальных температурных условиях.

Ключевые слова: Anethum graveolens L., гетероморфизм, местоположение семени, материнское растении, семена, прорастание, рост зародыша, термочувствительность.

Гетероморфизм - наличие на одном растении семян, различающихся по размерам, массе, окраске, морфологии, анатомии, характеру прорастания и другим признакам - широко представлен в растительном мире и присущ как диким, так и культурным формам (1-3). В семействах Asteraceae, Chenopodiaceae, Poaceae, Apeaceae и Brassicaceae выявлено значительное варьирование размера семян (4-7). Для некоторых видов, например Danthonia spicata (8), Heterosperma pinnatum (9), характерна дискретная изменчивость, другие, в частности Rubus ulmifolius (10), Raphanus raphanistrum (11), Rubus 
chamaemorus (12), демонстрируют непрерывное варьирование размера семян.

Между особями $(13-15)$ и в популяции $(16,17)$ широко распространена изменчивость семян по комплексу признаков, в том числе по посевным качествам (18-20). Разную всхожесть и требования к прорастанию, как правило, связывают с местоположением семян, формирующихся на различных метамерах материнского растения. Одно из основных объяснений этих различий состоит в том, что питательные ресурсы материнского растения распределяются между семенами неодинаково (21). Кроме того, семена развиваются в разное время, а следовательно, попадают в разные погодные условия. Одновременно изменяется физический возраст, физиологическое и биохимическое состояние материнского растения, что также отражается на метаболизме семян (22).

Среди овощных культур семейства Сельдерейные (Apiaceae) распространен гетероморфизм, обусловленный матрикальным фактором $(23,24)$. Растения характеризуются растянутым цветением и созреванием семян в зонтиках. S.D. Hendrix (25) показал, что размер и масса семян пастернака снижаются при увеличении порядка ветвления. J.N. Thompson отмечает (26), что варьирование размеров семян в пределах одного растения Lomatium grayi составляет $16 \%$. Влияние гетероморфизма семян зонтичных на их качество изучали многие исследователи. Так, Т.Н. Thomas с соавт. (27) установили, что семена моркови, собранные с первичных и вторичных зонтиков, при различных условиях проращивания имели неодинаковые показатели качества. В этой же работе показано влияние порядка ветвления на проявление покоя семян Apium graveolens и их чувствительность к GA4/7. Многими авторами показано, что качество семян моркови уменьшается по мере увеличения порядка ветвления (28-30).

Один из ключевых эндогенных факторов, влияющих на качество семян сельдерейных культур, - морфологическое недоразвитие зародыша (31-33), что накладывает особые требования на работу с такими семенами. При росте зародыш проходит несколько критических стадий, в которые он очень чувствителен к воздействующим факторам. Различные условия могут тормозить его рост, что впоследствии сказывается как на скорости прорастания, так и на числе проросших семян. Климатическая неустойчивость и вероятность аномальных погодных условий делают актуальной задачу изучения адаптационных реакций растений. Так, воздействию высокой температуры растения могут подвергаться на разных стадиях развития (34). Влияние этого фактора на прорастание семян рассматривается с точки зрения кардинальных температур $(35,36)$.

Оптимальная температура для семян большинства культур находится в диапазоне от 15 до $30{ }^{\circ} \mathrm{C}$, максимальная - от 30 до $40{ }^{\circ} \mathrm{C}$ (35). Для зародышей и интактных семян укропа, сформированных в соцветиях первого и второго порядков ветвления, кардинальную температуру не определяли. В большинстве работ влияние места формирования зонтика на посевные качества (28-30), а также действие на семена высокой температуры $(37,38)$ изучалось на растениях моркови. На укропе проводилось меныше подобных исследований (39). Рост зародыша в семенах после отделения от материнского растения оценивали в основном на диких видах сельдерейных $(40,41)$. Доразвитие зародыша с разных порядков и влияние стрессовых факторов на этот процесс в семенах зонтичных, в частности укропа, освещен скудно.

Ранее нами были рассмотрены особенности прорастания однородных партий семян овощных зонтичных культур при различных температурных режимах и проанализированы кинетические параметры, характеризующие этот процесс (42). 
В настоящей работе при проращивании интактных семян укропа впервые выявлена значительная термочувствительность зародышей из семян, сформированных в соцветиях второго порядка ветвления, к длительному действию супероптимальной температуры. При воздействии высокой температуры происходило угнетение роста зародышей и, как следствие, прорастания интактных семян укропа, полученных из соцветий второго порядка.

Нашей целью было изучить влияние матрикального фактора, а также высокой температуры на рост зародыша и прорастание интактных семян укропа, сформированных в соцветиях разных порядков ветвления.

Методика. Опыты проводили в 2015-2016 годах во Всероссийском НИИ овощеводства - филиал ФГБНУ Федеральный научный центр овощеводства. Объектом исследований служили семена укропа (Anethum graveolens L.) позднеспелого сорта Кентавр, сформированные в соцветиях первого (1п) и второго (2п) порядков ветвления. Растения сорта Кентавр в фазе цветения достигают высоты 100-110 см, раскидистые, сильно облиственные. Зонтик большого размера, выпуклый, многолучевой. В условиях Московской области растения формируют полноценные зонтики на осях двух порядков.

Семена получали с растений укропа, выращенных в открытом грунте (Московская обл., 55³6 $\mathrm{N} 38^{\circ} 1^{\prime} \mathrm{E}$ ). Посев проводили во II декаде мая рядами по схеме $45 \times 10$ см. Глубина заделки составляла 1,5 см, норма высева 1-2 г/м². Делянки площадью 10 м $^{2}$ размещали рандомизированным методом. Повторность опыта 3-кратная. Уборку проводили на 50-е сут после цветения зонтиков 1п. Выбирали 90 растений и срезали зонтики двух порядков. Семена сушили и хранили в естественных условиях в лаборатории в течение 6 мес. После хранения измеряли влажность и массу 1000 семян.

Эксперименты проводили в термостате ТС 1/80 (ОАО «Смоленское СКТБ СПУ», Россия) с контролируемой температурой. Чтобы определить критическую температуру для роста зародыша при проращивании и прорастании интактных семян 1п и 2п, воздействовали широким диапазоном высоких температур: $20{ }^{\circ} \mathrm{C}$ (контроль) - среднеоптимальная температура для семян, не находящихся в состоянии покоя (43); 25, 30, 35 и $40{ }^{\circ} \mathrm{C}$. Субстрат постоянно поддерживали во влажном состоянии. Влажности воздуха в камере составляла 90-95 \%. Перед началом эксперимента семена стерилизовали $0,125 \%$ раствором гипохлорита натрия в течение 5 мин, а затем промывали дистиллированной водой. Эксперименты продолжались в течение 21 сут без доступа света.

Для исследования динамики роста зародыша в чашки Петри (9 см) на лист фильтровальной бумаги, смоченной дистиллированной водой, закладывали порции интактных семян (четыре повторности по 10 семян для каждых суток наблюдений). На случай гибели или обнаружения семян без зародыша закладывали страховочные семена (четыре повторности по 100 семян). Оттуда при необходимости случайным образом отбирали нужное число семян для анализа. Ежесуточно для каждого варианта случайным образом отбирали чашки Петри, находящиеся там семена разрезали лезвием и извлекали зародыш. За время эксперимента проанализировали около 6000 семян. Семена разрезали пополам, измеряли длину зародыша. Для проросших семян использовали показатель «критическая длина зародыша» длина зародыша после разрыва семенной кожуры, но до появления корешка (44). Изображения зародышей получали с помощью микроскопа Levenhuk 670T («Levenhuk», США) с ахроматическим объективом 4×, соединенным с видеоокуляром ScopeTek DCM 300 MD («ScopeTek», Китай). Размер зародышей определяли с использованием программного обеспечения для ана- 
лиза изображений Scope Photo (Image Software V. 3.1.386). Рассчитывали соотношение длины зародыша (E) к длине эндосперма (S) (E:S ratio). Размер эндосперма измеряли штангенциркулем. E:S ratio классифицировали по следующей шкале: 1 - 0,0-0,19 (длина зародыша менее 1/4 длины эндосперма, зародыш в стадии сердечка); 2 - 0,20-0,29 (длина зародыша 1/4 длины эндосперма, семядоли и корешок равной длины); $3-0,30-0,39$ (длина зародыша около $1 / 3$ от длины эндосперма, имеет выраженные семядоли и корешок); 4 - 0,40-0,59 (длина зародыша 1/2 от длины эндосперма, корешок длиннее семядолей); $5-0,60-0,79$ (длина зародыша $2 / 3$ длины эндосперма); 6 - 0,80-1,00 (длина зародыша почти равна длине эндосперма) (45).

Действие высокой температуры на прорастание семян оценивали по ее влиянию на проклевывание зародышевого корешка. О завершении прорастания судили по проклевыванию корешка. Порции интактных семян (4 повторности по 100 семян) проращивали, как описано выше. Ежесуточно оценивали число проклюнувшихся семян. Всего было проанализировано около 4000 семян. Проросшие семена удаляли. Продолжительность опыта -21 сут.

На основании полученных данных строили кривые роста зародыша и прорастания семян. При построении кривых роста зародыша использовали логистическую регрессию с четырьмя параметрами: $b$ - наклон кривой роста зародыша, с - нижняя точка кривой роста зародыша (соответствует начальной длине зародыша), d - верхняя точка кривой роста зародыша (соответствует максимальной длине зародыша при проращивании семян), e - время (сут), затраченное на рост 50 \% от длины зародыша, необходимой для прорастания семян. Для построения кривой прорастания семян использовали логистическую регрессию с тремя параметрами: $b-$ наклон кривой прорастания семян, d - верхняя точка кривой прорастания семян (соответствует проценту проросших семян во время эксперимента); е - время (сут) прорастания 50 \% семян из всех проросших $(46,47)$. Для расчета максимальной температуры, при которой возможен рост зародыша и прорастание семян, использовали логистическую регрессию.

Статистическую оценку различий проводили по разности параметров с использованием стандартной ошибки ( $\pm \mathrm{SEM})$ и критериев для нулевой гипотезы о том, что разность равна 0. Все данные перед началом анализа подвергали тестированию на нормальность распределения с использованием критерия Шапиро-Уилка (W, Shapiro-Wilk test). Двухфакторный дисперсионный анализ использовали для проверки влияния исследуемых факторов на рост зародыша и прорастания семян с предварительным преобразованием данных в корень угла-арксинус. Взаимосвязь между параметрами оценивали посредством корреляционного анализа Пирсона. Различия в каждой паре сравниваемых значений считали статистически значимыми при $\mathrm{p} \leq 0,05$.

Модели, представленные в статье, были реализованы в пакете расширения «drc» для программной среды R. Все статистические анализы выполняли в R версии 3.4 .3 (48).

Результаты. Масса 1000 семян укропа сорта Кентавр, полученных из зонтиков 1п в 2015 году, равнялась 1,50 г, из зонтиков 2п - 1,32 г; в 2016 году эти показателя составляли соответственно 1,59 и 1,41 г. Влажность семян после сушки составляла 12-13\%.

Увеличение температуры проращивания до максимальной $\left(40{ }^{\circ} \mathrm{C}\right)$ приводило к угнетению роста зародышей в семенах из соцветий как пер- 
вого, так и второго порядка ветвления $(\mathrm{p}<0,001)$ (рис. 1). При действии менее агрессивной температуры (30-35 $\left.{ }^{\circ} \mathrm{C}\right)$ проявлялись различия в термочувствительности зародышей. Сравнение кривых роста отчетливо выявило гетероморфность их начальной длины $(\mathrm{p}<0,001)$. Угнетение роста зародышей выражалось в уменьшении их максимальной длины при прора-

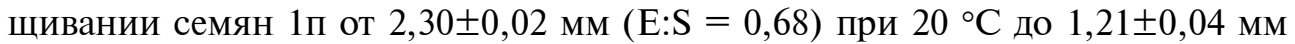
$(\mathrm{E}: \mathrm{S}=0,36)$ при $40{ }^{\circ} \mathrm{C}$ и семян $2 п-$ от $1,89 \pm 0,03$ мм $(\mathrm{E}: \mathrm{S}=0,62)$ при $20{ }^{\circ} \mathrm{C}$

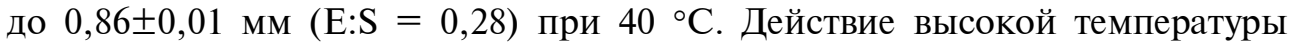
негативно отразилось на темпе роста зародышей. Так, время, затраченное на рост зародышей 1п при увеличении температуры до 25 и $35^{\circ} \mathrm{C}$, возрастало соответсвенно на $2,4 \pm 0,3(\mathrm{p}<0,001)$ и $5,3 \pm 0,9$ сут $(\mathrm{p}<0,001)$, зародышей 2 - на $2,9 \pm 0,8(\mathrm{p}<0,001)$ и $3,1 \pm 1,2$ сут $(\mathrm{p}=0,007)$ по сравнению с $20^{\circ} \mathrm{C}$. Темпы роста зародышей 1п и 2п на одинаковых стрессовых фонах различались несущественно. При увеличении температуры до $40{ }^{\circ} \mathrm{C}$ к 4-5-м сут исследования происходила полная остановка роста зародышей в семенах из зонтиков обоих порядков.

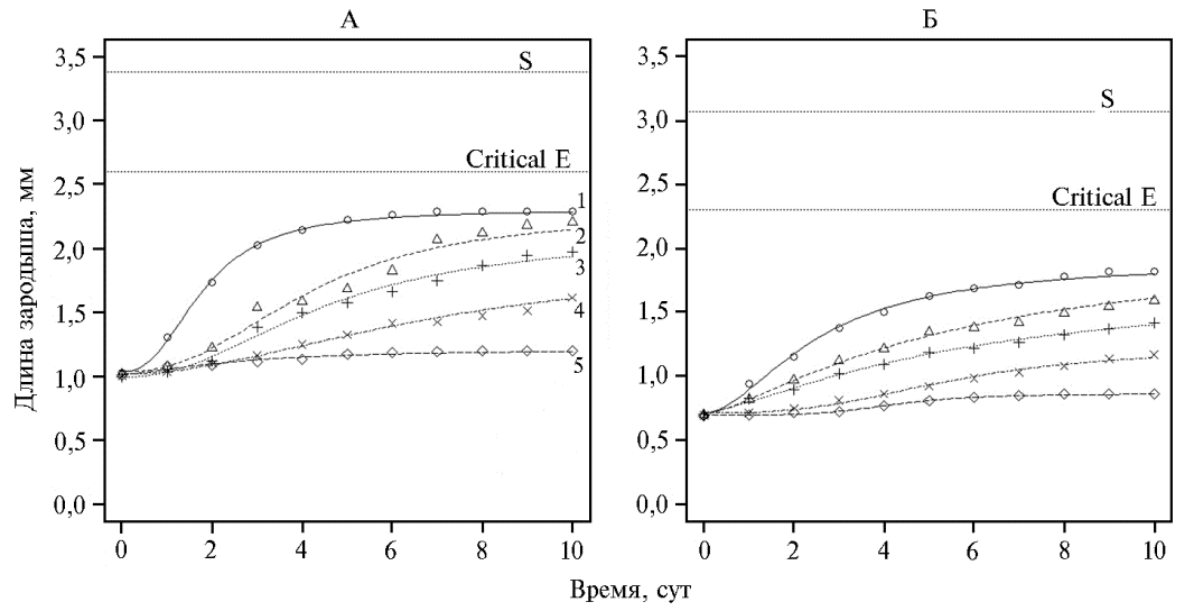

Рис. 1. Кривые роста зародыша при проращивании семян укропа (Anethum graveolens L.) позднеспелого сорта Кентавр в зависимости от высокотемпературного фактора и порядка ветвления материнского растения: А - первый порядок ветвления, Б - второй порядок ветвления; 1 $20{ }^{\circ} \mathrm{C}, 2-25{ }^{\circ} \mathrm{C}, 3-30{ }^{\circ} \mathrm{C}, 4-35{ }^{\circ} \mathrm{C}, 5-40{ }^{\circ} \mathrm{C} ; \mathrm{S}-$ длина эндосперма, Critical $\mathrm{E}-$ критическая длина зародыша (лабораторный опыт, 2015-2016 годы).

Как и в случае с ростом зародыша, при увеличении температуры происходило угнетение прорастания семян (р < 0,001), что выражалось в снижении скорости прорастания и уменьшении числа проросших семян (рис. 2). Средний процент прорастания для семян 1п снижался при повышении температуры до 30 и $35{ }^{\circ} \mathrm{C}$ по сравнению с $20{ }^{\circ} \mathrm{C}$ соответственно

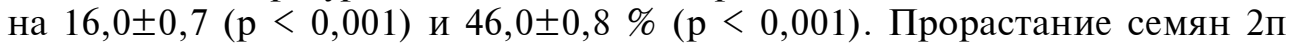
также существенно (p $<0,001)$ сокращалось. При $20^{\circ} \mathrm{C}$ процент прорастания семян 1п был на $19,0 \pm 0,63 \%$ (p < 0,001) выше, чем у семян 2П. При 30 и $35^{\circ} \mathrm{C}$ прорастание семян 2п по сравнению с 1п снижалось соответственно в 2,1 и 5,2 раза $(\mathrm{p}<0,001)$. Время прорастания $50 \%$ семян 1 п при 30 и $35^{\circ} \mathrm{C}$ было выше, чем при $20{ }^{\circ} \mathrm{C}$ на $2,3 \pm 0,1$ ( $\left.<<0,001\right)$ и $3,5 \pm 0,2$ сут $(\mathrm{p}<0,001)$. Для семян 2 п при $30{ }^{\circ} \mathrm{C}$ этот параметр увеличивался на $3,7 \pm 0,2$ сут $(\mathrm{p}<0,001)$ по сравнению с $20^{\circ} \mathrm{C}$.

Максимальная длина зародыша при проращивании семян оказывала значительное влияние на число проросших семян. Коэффициент корреляции Пирсона между параметрами составлял $r=0,946(t=25,85 ; \mathrm{p}<0,001)$. В связи с этим мы более подробно проанализировали их с помощью 
двухфакторного дисперсионного анализа и обнаружили существенное влияние высокотемпературного фактора (57 \%, $\mathrm{F}=415,3, \mathrm{p}<0,001)$, фактора места формирования на материнском растении $(37,2 \%, \mathrm{~F}=270,5$, $\mathrm{p}<0,001)$, года выращивания $(5,3 \%, \mathrm{~F}=38,5 ; \mathrm{p}<0,001)$ и их взаимодействия $(0,37 \%, \mathrm{~F}=2,7, \mathrm{p}=0,004)$ на максимальную длину зародыша при проращивании семян. Данные показывают, что годы выращивания имели самую низкую долю влияния. Значительное влияние на долю проросших семян оказывали высокотемпературный фактор $(71,0 \%, \mathrm{~F}=1013,1$, $\mathrm{p}<0,001)$, место формирования на материнском растении $(27,6 \%, \mathrm{~F}=395,1$, $\mathrm{p}<0,001)$, год выращивания $(0,9 \%, \mathrm{~F}=12,9, \mathrm{p}=0,001)$ и взаимодействие изученных факторов $(0,7 \%, \mathrm{~F}=10,1, \mathrm{p}<0,001)$. Как видно, действие высокой температуры имело определяющее значение при росте зародыша в процессе проращивания и при прорастании интактных семян укропа.

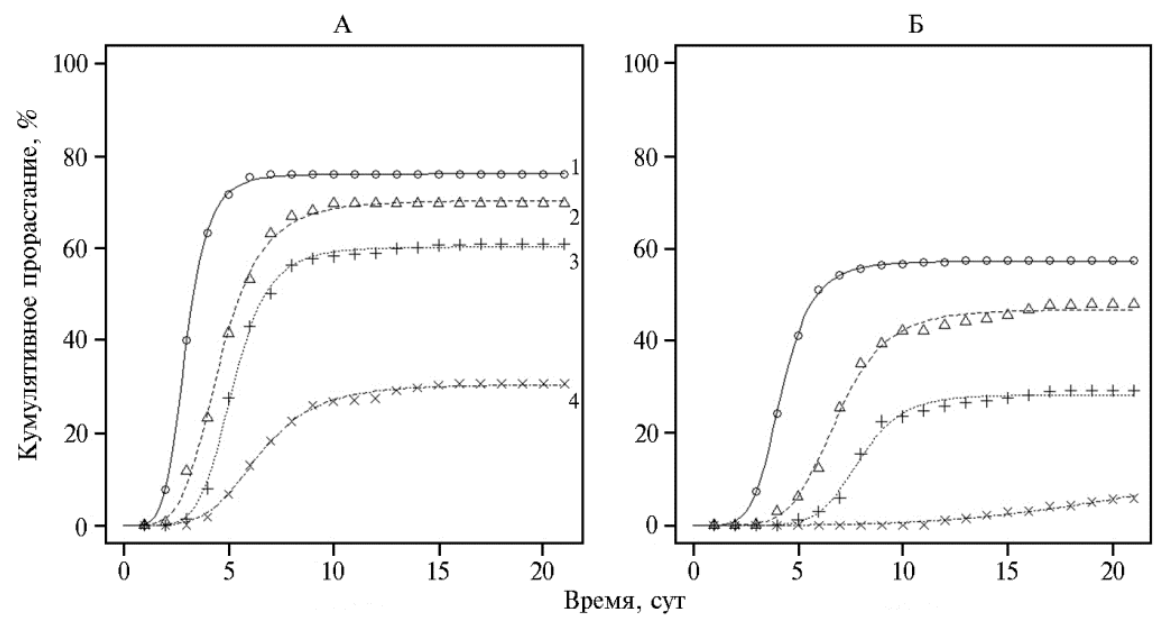

Рис. 2. Кривые прорастания семян укропа (Anethum graveolens L.) позднеспелого сорта Кентавр в зависимости от высокотемпературного фактора и порядка ветвления материнского растения: А первый порядок ветвления, Б - второй порядок ветвления; $1-20{ }^{\circ} \mathrm{C}, 2-25{ }^{\circ} \mathrm{C}, 3-30{ }^{\circ} \mathrm{C}$, $4-35{ }^{\circ} \mathrm{C}$ (лабораторный опыт, 2015-2016 годы). При температуре $40{ }^{\circ} \mathrm{C}$ прорастания не происходило, в связи с чем кривые на графике не представлены.

A

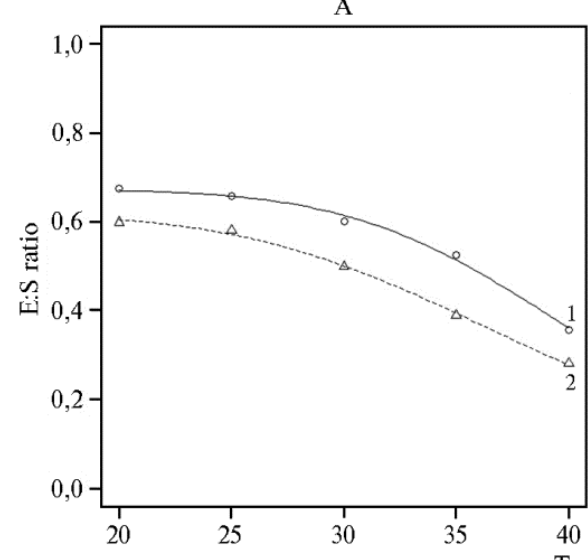

Б

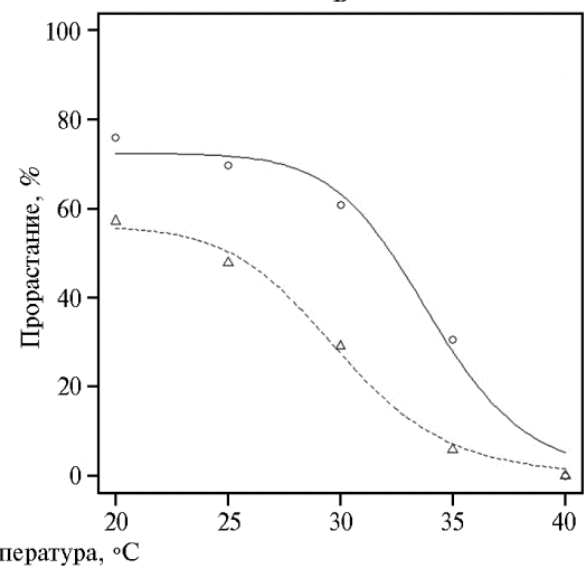

Рис. 3. Кривые «дозахэффект» действия теплового фактора на максимальную длину зародышей укропа (Anethum graveolens L.) позднеспелого сорта Кентавр при проращивании семян (для более корректного анализа проведен перерасчет с использованием соотношения длины зародыша к длине эндосперма, E:S ratio) (A) и процент проросших семян (Б) в зависимости от порядка ветвления: 1 - первый порядок ветвления, 2 - второй порядок ветвления (лабораторный опыт, 2015-2016 годы). 
Максимальная температура, при которой происходил рост зародышей $1 п$, составляла $40 \pm 0,4{ }^{\circ} \mathrm{C}$, зародышей $2 п-38 \pm 0,5{ }^{\circ} \mathrm{C}(\mathrm{p}<0,001)$. Максимальная температура, допускающая проклевывание не менее $50 \%$ жизнеспособных семян 1 п, составляла $34 \pm 0,3{ }^{\circ} \mathrm{C}$, семян $2 \Pi-30 \pm 0,4{ }^{\circ} \mathrm{C}$ $(\mathrm{p}<0,001)$ (рис. 3).

Для сельдерейных культур характерно наличие в зрелых семенах дифференцированных зародышей, однако определенная доля семян имеет в различной степени недоразвитые зародыши. Их дальнейшее развитие происходит уже после отделения семени от материнского растения, в процессе проращивания, и имеет свои особенности $(49,50)$. Мы показали, что зародыши из семян, сформированных в соцветиях разных порядков ветвления, различаются не только по физической длине, но и по классам соотношений E:S. Начальное значение E:S у зародышей 1п составляло $0,31 \pm 0,01$. Для них было характерно наличие выраженных семядолей и корешка. Для зародышей 2п начальное соотношение составляло $0,23 \pm 0,01$. При этом семядоли и корешок были равной длины, слабо выраженными. То есть уже на первых этапах проращивания зародыши 1п обладали преимуществом над зародышами 2п. Более крупные семена 1п накапливали больше питательных веществ и имели потенциальный ресурс для поддержания высокого темпа роста зародыша. Согласно полученным данным, для наклевывания семени, зародышу было необходимо развиться минимум на 40-50 \% от своей первоначальной длины. При этом темпы роста зародыша (см. рис. 1) в условиях оптимальной и стрессовой температуры существенно различались в зависимости от места формирования. В результате число проросших семян 1п оказалось выше, чем семян 2п (см. рис. 2).

В непредсказуемых условиях выращивания разновременное созревание или прорастание семян эффективно снижает риск гибели потомства и увеличивает репродуктивный успех. Можно ожидать, что роль варьирования морфометрических параметров семян в пределах отдельных растений возрастет, если окружающая среда будет непредсказуемой (51-53). Следовательно, с эволюционной точки зрения гетероморфность семян - адаптивно положительное явление. Однако в агрономической практике она, как правило, становится причиной снижения числа и скорости прорастания семян, изреженности и неоднородности проростков и растений $(54,55)$. Проблему гетероморфности можно решить, совершенствуя процесс производства и доработки семян.

Тепловой стресс - один из самых значимых абиотических факторов, определяющих продуктивность многих сельскохозяйственных культур (56$58)$, в частности сельдерейных $(59,60)$. Считается, что превышение оптимальной температуры для конкретного вида растений на $10-15{ }^{\circ} \mathrm{C}$ вызывает цепь ответных реакций, направленных на передачу стресс-сигнала и повышение устойчивости, выражающейся в сдвиге метаболических реакций и физиологических процессов (61-63). Семена, не находящиеся в состоянии покоя, обычно способны прорастать в широком диапазоне температур. Однако постоянная температура около $40{ }^{\circ} \mathrm{C}$ в период набухания оказывается критической для семян многих видов и затрудняет прорастание (64).

Мы выявили значительную чувствительность зародышей укропа к действию высокой температуры в зависимости от порядка ветвления. Физиологическим ответом на непрерывное действие повышенных температур (30-40 $\left.{ }^{\circ} \mathrm{C}\right)$ было прогрессирующее угнетение роста зародышей и прорастания семян. При температурах от 25 до $35^{\circ} \mathrm{C}$ наблюдались различия в реакции зародышей, а также семян на действие стрессора. Рост зародыша и 
прорастание замедлялись в той или иной степени при повышении температуры набухания до $30-35{ }^{\circ} \mathrm{C}$ для семян 1п и до 25-30 ${ }^{\circ} \mathrm{C}-$ для семян 2п.

Влияние температуры на прорастание семян было изучено в нескольких работах (65-67). В частности, исследовалось сочетание факторов засоления, водного и температурных режимов на всхожесть семян (68-70). Однако влияние фактора матрикальной разнокачественности зародыша на устойчивость к высокой температуре при прорастании не рассматривалось. В наших опытах максимальная температура прорастания, допускающая проклевывание не менее 50 \% жизнеспособных семян и рост зародыша, существенно различалась для разных порядков ветвления. При приближении к критической температуре $\left(40{ }^{\circ} \mathrm{C}\right)$ различия нивелировались. Зародыши 1п и 2п обнаруживали значительную чувствительность к продолжительному непрерывному действию повышенных температур в период набухания и не были способны к прорастанию при $40{ }^{\circ} \mathrm{C}$. Интактные семена оказались, более чувствительны к действию высокой температуры, чем зародыши.

Другой важный аспект процесса прорастания семян, который может зависеть от температуры, - скорость прорастания. Наши результаты показали, что для укропа скорость прорастания интактных семян линейно увеличивалась в интервале температур до их оптимального значения, а затем снижалась. Подобные линейные отношения между скоростью прорастания и температурой другие исследователи наблюдали у проса (71), басии веничной (72), куфеи липчайшей (73), подорожника яйцевидного (74) и некоторых видов лекарственных растений (75). Мы выявили существенные различия в скорости прорастания семян укропа 1п и 2п в условиях высокотемпературного стресса.

Термочувствительность зародышей, обусловленная их морфологическим недоразвитием, - одна из основных причин медленного, неоднородного и неполного прорастания популяции семян в сверхоптимальных температурных условиях. Моделирование процесса прорастания семян, имеющих недоразвитый зародыш, представляет интерес как для селекционной практики, так и для совершенствования технологии подготовки семян к посеву. Методы, основанные на изучении кинетики роста зародыша и прорастания гетероморфных семян укропа в условиях широкого диапазона температур, могут быть использованы в селекции на жаростойкость.

Таким образом, начальное развитие зародышей укропа сорта Кентавр, которые закладываются во время формирования семян на материнском растении, влияет на последующее прорастание семян. Зародыши из семян, сформированных в соцветиях разных порядков ветвления (первого порядка - 1п, второго - 2п) различались по морфометрическим параметрам. Начальные размеры зародышей 1п были существенно больше размеров зародышей 2п. Зародыши 1п оказались более развиты и менее чувствительны к действию высокой температуры при прорастании. Факторы высоких температур значительно влиял на скорость роста зародыша и прорастание семян, а также на число проросших семян, причем семена были более чувствительны к высоким температурам, чем зародыши. Существенные различия в термочувствительности зародышей и интактных семян, обусловленные местом формирования на материнском растении, выявлены в процессе проращивания уже при температуре 20-30 ${ }^{\circ} \mathrm{C}$. Повышение температуры до $35-40{ }^{\circ} \mathrm{C}$ ингибировало рост зародыша и прорастание семян, сформированных в соцветиях обоих порядков ветвления. При этом максимальная температура, при которой возможен рост зародышей укропа сорта 
Кентавр, сформированных в соцветиях первого порядка, была существенно выше, чем для семян из соцветий второго порядка. Как показали исследования, температурный фактор в значительной степени определяет доразвитие зародыша в период, предшествующий наклевыванию семян, что может быть эффективным методом предпосевной обработки.

1 ФГБНУ Федеральный научный центр овощеводства,

Поступила в редакцию

143080 Россия, Московская обл., Одинцовский р-н, 12 октября 2019 года

пос. ВНИИССОК, ул. Селекционная, 14,

e-mail: alex-soldat@mail.ru $₫$, afb@mail.ru, ivanova_170@mail.ru,

oleg.rasin@gmail.com,777razin@rambler.ru;

2ФГБНУ Всероссийский НИИ лекарственных

и ароматических растений,

117216 Россия, г. Москва, ул. Грина, 7,

e-mail: dbaleev@gmail.com;

${ }^{3}$ НИИ физико-химической биологии им. А.Н. Белозерского,

ФГБОУ ВПО МГУ им. М.В. Ломоносова,

119992 Россия, г. Москва, Ленинские горы, 1, стр. 40,

e-mail: nazarovpa@gmail.com

Sel'skokhozyaistvennaya biologiya [Agricultural Biology], 2020, V. 55, № 5, pp. 932-944

\title{
IMPACT OF HIGH TEMPERATURE ON GROWTH OF EMBRYO AND GERMINATION OF HETEROMORPHIC SEEDS OF Anethum graveolens L. (Apiaceae)
}

\author{
A.V. Soldatenko ${ }^{1}$, A.F. Buharov ${ }^{1}$, D.N. Baleev ${ }^{2}$, M.I. Ivanova ${ }^{1}$, P.A. Nazarov³, \\ O.A. Razin 1 , A.F. Razin 1
}

${ }^{1}$ Federal Research Center for Vegetable Growing, 14, ul. Selektsionnaya, pos. VNIISSOK, Odintsovskii Region, Moscow Province, 143080 Russia, e-mail alex-soldat@mail.ru (corresponding author $₫$ ), afb@mail.ru, ivanova_170@mail.ru, oleg.rasin@gmail.com,777razin@rambler.ru;

2All-Russian Research Institute of Medicinal and Aromatic Plants, 7, ul. Grina, Moscow, 117216 Russia, e-mail dbaleev@gmail.com;

${ }_{3}^{3}$ Belozersky Research Institute of Physico-Chemical Biology, Lomonosov Moscow State University, 1/40, Leninskie gory, Moscow, 119992 Russia e-mail nazarovpa@gmail.com

ORCID:

Soldatenko A.V. orcid.org/0000-0002-9492-6845

Buharov A.F. orcid.org/0000-0002-1228-0594

Baleev D.N. orcid.org/0000-0002-1228-0594

Ivanova M.I. orcid.org/0000-0001-7326-2157

The authors declare no conflict of interests

Received October 12, 2019

Nazarov P.A. orcid.org/0000-0003-1857-323X

Razin O.A. orcid.org/0000-0002-4844-938X

Razin A.F. orcid.org/0000-0003-4509-6774

doi: 10.15389/agrobiology.2020.5.932eng

\section{Abstract}

Heteromorphism is widespread in nature and manifests itself in the variation of various parameters of seeds within individual individuals and populations. Dill (Anethum graveolens L.) seeds are characterized by heteromorphism caused by the maternal factor. First of all, the maternal factor effects on the size of the seeds, in this case a variation in the size of the embryo can be observed. The study of the reaction of such seeds to the action of abnormal weather conditions is an urgent task. High temperature is one of the unfavorable abiotic factors that plants can be exposed to at different stages of development. In the present study, a significant thermal sensitivity to the long-term effect of suboptimal (higher than the optimal) temperature of embryos from dill seeds, formed in inflorescences of the second order of branching, was revealed for the first time. Under the influence of high temperature, the growth of embryos was inhibited. As a result, germination of intact dill seeds obtained from second-order inflorescences was observed. This work is devoted to the study of the effect of high temperature on the growth of the embryo and the germination of intact dill seeds obtained from different orders of branching. The study aimed to determine the influence of the maternal factor, as well as high temperature on the growth of the embryo during germination and on the germination of intact dill seeds formed in inflorescences of different orders of branching. The research was conducted in 2015-2016 at the All-Russian Research Institute for Vegetable Growing, Branch of the Federal Scientific Vegetable Center, with the late-ripening dill variety Centaur seeds, formed in inflorescences of the first and second orders of branching. The seeds were obtained from dill plants grown in the open field. Harvesting was carried out on day 50 after flowering of 1 st order umbrellas. The experiments were carried out in a temperature-controlled thermostat. To determine the critical temperature for the 
growth of the embryo during germination and germination rate of intact seeds formed in different orders of branching, a wide temperature range was applied, $20^{\circ} \mathrm{C}$ as control, and $25,30,35$ and $40{ }^{\circ} \mathrm{C}$. Using the morphometric method of analysis, we studied the growth of the embryo, as well as the dynamics of the germination of intact seeds against the high temperatures background. The data obtained were used to calculate the parameters and plot the embryo growth curve, as well as the germination curve of intact seeds. Logistic regression was used to calculate the maximum suboptimal temperature at which embryo growth and seed germination are possible. On the basis of experimental data, we have shown that embryos, formed at different branching orders of the mother plant, have different stages of development. The initial dimensions of the embryo of the first branching order are $30 \%$ higher than the second $(\mathrm{p}<0.001)$. Under the action of a temperature of $30-35{ }^{\circ} \mathrm{C}$, differences appeared in the thermal sensitivity of the embryos and the growth rate of the embryos. The effect of high temperatures is crucial for the growth of the embryo $(57.0 \% ; \mathrm{F}=415.3, \mathrm{p}<0.001)$ and germination of dill seeds $(37.2 \% ; \mathrm{F}=270.5, \mathrm{p}<0.001)$. The maximum temperature at which the growth is possible is $40 \pm 0.4{ }^{\circ} \mathrm{C}$ for the first-order embryo, and $38 \pm 0.5{ }^{\circ} \mathrm{C}$ for the secondorder embryo $(\mathrm{p}<0.001)$. The maximum temperature allowing for germination of at least $50 \%$ of viable first-order seeds is $34 \pm 0.3{ }^{\circ} \mathrm{C}$, for the second-order $30 \pm 0.4{ }^{\circ} \mathrm{C}(\mathrm{p}<0.001)$. The seeds are more sensitive to high temperatures than the embryos, and the growth of the embryo has a significant effect on seed germination $(r=0.946 ; t=25.85 ; \mathrm{p}<0.001)$. Our studies have shown that the temperature sensitivity of second-order embryos, which is clearly manifested against the background of morphological underdevelopment, is one of the main reasons for the slow, inhomogeneous and incomplete germination of the dill seed population under suboptimal temperature conditions.

Keywords: Anethum graveolens L., embryo growth, heteromorphism, seed position, mother plant, seed germination, thermosensitivity.

\section{R E F E R E N C E S}

1. Sun H.Z., Lu J.J., Tan D.Y., Baskin J.M., Baskin C.C. Dormancy and germination characteristics of the trimorphic achenes of Garhadiolus papposus (Asteraceae), an annual ephemeral from the Junggar Desert, China. South African Journal of Botany, 2009, 75(3): 537-545 (doi: 10.1016/j.sajb.2009.05.001).

2. Yao S., Lan H., Zhang F. Variation of seed heteromorphism in Chenopodium album and the effect of salinity stress on the descendants. Annals of Botany, 2010, 105(6): 1015-1025 (doi: 10.1093/aob/mcq060).

3. Cao J., Lv X.Y., Chen L., Xing J.J., Lan H.Y. Effects of salinity on the growth, physiology and relevant gene expression of an annual halophyte grown from heteromorphic seeds. AoB PLANTS, 2015, 7: plv112 (doi: 10.1093/aobpla/plv112).

4. Harper J.L. Population biology of plants. London, Academic Press, 1977.

5. Mandák B. Seed heteromorphism and the life cycle of plants: a literature review. Preslia-Prague, 1997, 69: 129-159.

6. Imbert E. Ecological consequences and ontogeny of seed heteromorphism. Perspectives in Plant Ecology, Evolution and Systematics, 2002, 5(1): 13-36 (doi: 10.1078/1433-8319-00021).

7. Moles A.T., Westoby M. Seed size and plant strategy across the whole life cycle. Oikos, 2006, 113(1): 91-105 (doi: 10.1111/j.0030-1299.2006.14194.x).

8. Clay K. The differential establishment of seedlings from chasmogamous and cleistogamous flowers in natural populations of the grass Danthonia spicata (L.) Beauv. Oecologia, 1983, 57: 183-188 (doi: 10.1007/BF00379579).

9. Venable D.L., Burquez A., Corral G., Morales E., Espinosa F. The ecology of seed heteromorphism in Heterosperma pinnatum in Central Mexico. Ecology, 1987, 68(1): 65-76 (doi: 10.2307/1938805).

10. Jordano P. Seed weight variation and differential avian dispersal in blackberries Rubus ulmifolius. Oikos, 1984, 43(2): 149-153 (doi: 10.2307/3544762).

11. Stanton M.L. Seed variation in wild radish: effect of seed size on components of seedling and adult fitness. Ecology, 1984, 65(4): 1105-1112 (doi: 10.2307/1938318).

12. Agren J. Seed size and number in Rubus chamaemorus: between-habitat variation, and effects of defoliation and supplemental pollination. Journal of Ecology, 1989, 77(4): 1080-1092 (doi: 10.2307/2260824).

13. Venudevan B., Srimathi P., Natarajan N., Vijayakumar R.M. Influence of fruit polymorphism on seed and seedling quality characters of bael (Aegle marmelos) the endangered medicinal tree. Asian Journal of Crop Science, 2013, 5(4): 452-458 (doi: 10.3923/ajcs.2013.452.458).

14. Bhatt A., Santo A. Germination and recovery of heteromorphic seeds of Atriplex canescens (Amaranthaceae) under increasing salinity. Plant Ecology, 2016, 217: 1069-1079 (doi: 10.1007/s11258-016-0633-6).

15. García-Beltrán J.A., Barrios D., Cuza-Pérez A. Heteromorphism in seeds of Leptocereus 
scopulophilus (Cactaceae) from Pan de Matanzas, Cuba. Seed Science Research, 2017, 27(4): 311 320 (doi: 10.1017/s0960258517000289).

16. Leverett L.D., Jolls C.L. Cryptic seed heteromorphism in Packera tomentosa (Asteraceae): differences in mass and germination. Plant Species Biology, 2014, 29(2): 169-180 (doi: 10.1111/1442-1984.12011).

17. Souza M.L., Fagundes M. Seed size as key factor in germination and seedling development of Copaifera langsdorffii (Fabaceae). American Journal of Plant Sciences, 2014, 5(17): 2566-2573 (doi: 10.4236/ajps.2014.517270).

18. van Mölken T., Jorritsma-Wienk L.D., van Hoek P.H.W., de Kroon H. Only seed size matters for germination in different populations of the dimorphic Tragopogon ratensis subsp. pratensis (Asteraceae). American Journal of Botany, 2005, 92(3): 432-437 (doi: 10.3732/ajb.92.3.432).

19. Baskin J.M., Lu J.J., Baskin C.C., Tan D.Y. The necessity for testing germination of fresh seeds in studies on diaspore heteromorphism as a life-history strategy. Seed Science Research, 2013, 23(2): 83-88 (doi: 10.1017/s096025851300010x).

20. Tongshun W., Hongling W., Lei W., Baoping S. Germination of heteromorphic seeds of Atriplex aucheri and its hormonal explanation. Vegetos - An International Journal of Plant Research, 2014, 27(1): 103-107 (doi: 10.5958/j.2229-4473.27.1.017).

21. Halloran G.M., Collins W.J. Physiological predetermination of the order of hardseededness breakdown in subterranean clover (Trifolium subterraneum L.). Annals of Botany, 1974, 38(5): 1039-1044 (doi: 10.1093/oxfordjournals.aob.a084894).

22. Baskin C.C., Baskin J.M. Seeds: ecology, biogeography, and evolution of dormancy and germination. San Diego, Academic Press, 1998.

23. Gray D., Steckel J.R.A. Parsnip (Pastinaca sativa) seed production: effects of seed crop plant density, seed position on the mother plant, harvest date and method, and seed grading on embryo and seed size and seedling performance. Annals of Applied Biology, 1985, 107(3): 559-570 (doi: 10.1111/j.1744-7348.1985.tb03172.x).

24. Bianco V.V., Damato G., Defilippis R. Umbel position on the mother plant: «seed» yield and quality of seven cultivars of Florence fennel. Acta Horticulturae, 1994, 362: 51-58 (doi: 10.17660/actahortic.1994.362.5).

25. Hendrix S.D. Variation in seed weight and its effects on germination in Pastinaca sativa L. (Umbelliferae). American Journal of Botany, 1984, 71(6): 795-802 (doi: 10.1002/j.15372197.1984.tb14144.x).

26. Thompson J.N. Variation among individual seed masses in Lomatium grayi (Umbelliferae) under controlled conditions: magnitude and partitioning of the variance. Ecology, 1984, 65(2): 626-631 (doi: 10.2307/1941425).

27. Thomas T.H., Gray D., Biddington N.L. The influence of the position of the seed on the mother plant on seed and seedling performance. Acta Horticulturae, 1978, 83: 57-66 (doi: 10.17660/actahortic.1978.83.7).

28. Szafiroska A.I. The correlation between mother plant architecture, seed quality and field emergence of carrot. Acta Horticulturae, 1994, 354: 93-98 (doi: 10.17660/actahortic.1994.354.10).

29. Corbineau F., Picard M.A., Bonnet A., Côme D. Effects of production factors on germination responses of carrot seeds to temperature and oxygen. Seed Science Research, 1995, 5(3): 129-135 (doi: 10.1017/s0960258500002749).

30. Panayotov N. Heterogeneity of carrot seeds depending on their position on the mother plant. Folia Horticulturae, 2010, 22(1): 25-30 (doi: 10.2478/fhort-2013-0147).

31. Scholten M., Donahue J., Shaw N.L., Serpe M.D. Environmental regulation of dormancy loss in seeds of Lomatium dissectum (Apiaceae). Annals of Botany, 2009, 103(7): 1091-1101 (doi: 10.1093/aob/mcp038).

32. Hawkins T.S., Baskin C.C., Baskin J.M. Morphophysiological dormancy in seeds of three eastern North American Sanicula species (Apiaceae subf. Saniculoideae): evolutionary implications for dormancy break. Plant Species Biology, 2010, 25(2): 103-113 (doi: 10.1111/j.14421984.2010.00273.x).

33. Vandelook F., Janssens S.B., Probert R.J. Relative embryo length as an adaptation to habitat and life cycle in Apiaceae. New Phytologist, 2012, 195(2): 479-487 (doi: 10.1111/j.14698137.2012.04172.x).

34. Alvarado V., Bradford K.J. A hydrothermal time model explains the cardinal temperature for seed germination. Plant, Cell and Environment, 2002, 25(8): 1061-1069 (doi: 10.1046/j.13653040.2002.00894.x).

35. Sarmadnia G.H. Seed technology. Mashhad University Press, 1997.

36. Yan W., Hunt L.A. An equation for modeling the temperature response of plants using only the cardinal temperatures. Annals of Botany, 1999, 84(5): 607-614 (doi: 10.1006/anbo.1999.0955).

37. Pereira R.S., Nascimento W.M., Vieira J.V. Carrot seed germination and vigor in response to temperature and umbel orders. Scientia Agricola, 2008, 65(2): 145-150 (doi: 10.1590/s010390162008000200006).

38. Nascimento W.M., Pereira R.S., Vieira J.V., Cantliffe D.J. Carrot seed germination at high 
temperature conditions. Acta Horticulturae, 2012, 936: 133-138 (doi: 10.17660/actahortic.2012.936.15).

39. Hołubowicz R., Morozowska M. Effect of umbel position on dill (Anethum graveolens L.) plants growing in field stands on selected seed stalk features. Folia Horticulturae, 2011, 23(2): 157-163 (doi: 10.2478/v10245-011-0024-3).

40. Vandelook F., Bolle N., Van Assche J.A. Seed dormancy and germination of the European Chaerophyllum temulum (Apiaceae), a member of a trans-Atlantic genus. Annals of Botany, 2007, 100(2): 233-239 (doi: 10.1093/aob/mcm090).

41. Vandelook F., Bolle N., Van Assche J.A. Morphological and physiological dormancy in seeds of Aegopodium podagraria (Apiaceae) broken successively during cold stratification. Seed Science Research, 2009, 19(2): 115-123 (doi: 10.1017/s0960258509301075).

42. Baleev D.N., Bukharov A.F. Ovoshchi Rossii, 2012, 3(16): 38-46 (in Russ.).

43. Nikolaeva M.G., Lyanguzova I.V., Pozdova L.M. Biologiya semyan [Seed biology]. St. Petersburg, 1999 (in Russ.).

44. Vandelook F., Van Assche J.A. Temperature, requirements for seed germination and seedling development determine timing of seedling emergence of three monocotyledonous temperate forest spring geophytes. Annals of Botany, 2008, 102(5): 865-875 (doi: 10.1093/aob/mcn 165).

45. Necajeva J., Ievinsh G. Seed dormancy and germination of an endangered coastal plant Eryngium maritimum (Apiaceae). Estonian Journal of Ecology, 2013, 62(2): 150-161 (doi: 10.3176/eco.2013.2.06).

46. Ritz C., Pipper C.B., Streibig J.C. Analysis of germination data from agricultural experiments. European Journal of Agronomy, 2013, 45: 1-6 (doi: 10.1016/j.eja.2012.10.003).

47. Ritz C., Baty F., Streibig J.C., Gerhard D. Dose-response analysis using R. PLoS ONE, 2015, 10(12): e0146021 (doi: 10.1371/journal.pone.0146021).

48. R Development Core Team. $R$ : a language and environment for statistical computing. R Foundation for Statistical Computing, Vienna, Austria, 2011.

49. Martin A.C. The comparative internal morphology of seeds. The American Midland Naturalist, 1946, 36(3): 513-660 (doi: 10.2307/2421457).

50. Stokes P.A physiological study of embryo development in Heracleum sphondylium L.: I. The effect of temperature on embryo development. Annals of Botany, 1952, 16(3): 441-447 (doi: 10.1093/oxfordjournals.aob.a083326).

51. Galloway L.F., Etterson J.R., McGlothlin J.W. Contribution of direct and maternal genetic effects to life-history evolution. New Phytologist, 2009, 183(3): 826-838 (doi: 10.1111/j.14698137.2009.02939.x).

52. Dyer A.R., Brown C.S., Espeland E.K., McKay J.K., Meimberg H., Rice K.J. Synthesis: the role of adaptive trans-generational plasticity in biological invasions of plants. Evolutionary Applications, 2010, 3(2): 179-192 (doi: 10.1111/j.1752-4571.2010.00118.x).

53. Lerner P.D., Bai Y., Morici E.F.A. Does seed heteromorphism have different roles in the fitness of species with contrasting life history strategies? Botany, 2008, 86(12): 1404-1415 (doi: 10.1139/b08-106).

54. Gharoobi B. Effects of seed size on seedlings characteristics of five barley cultivars. Iranian Journal of Plant Physiology, 2011, 1(4): 265-270.

55. Nik M.M., Babaeian M., Tavassoli A. Effect of seed size and genotype on germination characteristic and seed nutrient content of wheat. Scientific Research and Essays, 2011, 6(9): 20192025 (doi: 10.5897/sre11.621).

56. Maraghni M., Gorai M., Neffati M. Seed germination at different temperatures and water stress levels, and seedling emergence from different depths of Ziziphus lotus. South African Journal of Botany, 2010, 76(3): 453-459 (doi: 10.1016/j.sajb.2010.02.092).

57. Wen B. Effects of high temperature and water stress on seed germination of the invasive species Mexican sunflower. PLoS ONE, 2015, 10: e0141567 (doi: 10.1371/journal.pone.0141567).

58. Chitwood J., Shi A., Evans M., Rom C., Gbur E.E., Motes D., Chen P., Hensley D. Effect of temperature on seed germination in spinach (Spinacia oleracea). HortScience, 2016, 51(12): 14751478 (doi: 10.21273/hortsci11414-16).

59. Nascimento W.M., Huber D.J., Cantliffe D.J. Carrot seed germination and respiration at high temperature in response to seed maturity and priming. Seed Science and Technology, 2013, 41(1): 164-169 (doi: 10.15258/sst.2013.41.1.19).

60. Nascimento W.M., Huber D.J., Cantliffe D.J. Carrot seed germination and ethylene production at high temperature in response to seed osmopriming. Horticultura Brasileira, 2013, 31(4): 554558 (doi: 10.1590/s0102-05362013000400008).

61. Wehmeyer N., Vierling E. The expression of small heat shock proteins in seeds responds to discrete developmental signals and suggests a general protective role in desiccation tolerance. Plant Physiology, 2000, 122(4): 1099-1108 (doi: 10.1104/pp.122.4.1099).

62. Wang W., Vinocur B., Shoseyov O., Altman A. Role of plant heat-shock proteins and molecular shaperones in the abiotic stress response. Trends in Plant Science, 2004, 9(5): 244-252 (doi: 10.1016/j.tplants.2004.03.006). 
63. Mahmood T., Safdar W., Abbasi B.H., Naqvi S.M.S. An overview on the small heat shock proteins. African Journal of Biotechnology, 2010, 9(7): 927-939 (doi: 10.5897/ajb09.006).

64. Bewley J.D., Black M. Physiology and biochemistry of seeds in relation to germination. Berlin, Heidelberg, Springer, 1982.

65. Cicek E., Tilki F. Effects of temperature, light and storage on seed germination of Ulmus glabra Huds. and U. laevis Pall. Pakistan Journal of Biological Sciences, 2006, 9(4): 697-699 (doi: 10.3923/pjbs.2006.697.699).

66. Martínez-Sánchez J.J., Conesa E., Vicente M.J., Jiménez A., Franco J.A. Germination responses of Juncus acutus (Juncaceae) and Schoenus nigricans (Cyperaceae) to light and temperature. Journal of Arid Environments, 2006, 66(1): 187-191 (doi: 10.1016/j.jaridenv.2005.11.004).

67. Zehtab-Salmasi S. Effects of salinity and temperature on germination of dill (Anethum graveolens L.). Plant Sciences Research, 2008, 1(1): 27-29.

68. Khan M.A., Ungar I.A. Effect of thermoperiod on recovery of seed germination of halophytes from saline conditions. American Journal of Botany, 1997, 84(2): 279-283 (doi: 10.2307/2446089).

69. Khan M.A., Gul B., Weber D.J. Seed germination in relation to salinity and temperature in Sarcobatus vermiculatus. Biologia plantarum, 2001, 45(1): 133-135 (doi: 10.1023/a:1015133515568).

70. Pompelli M.F., Fernandes D., Guerra M.P. Germination of Dyckia encholirioides (Gaudichaud) Mez var. encholiriodies under saline conditions. Seed Science and Technology, 2006, 34(3): 759763 (doi: 10.15258/sst.2006.34.3.24).

71. Kamkar B., Koochaki A., Mahallati M.N., Moghaddam P.R. Cardinal temperatures for germination in three millet species. Asian Journal of Plant Sciences, 2006, 5(2): 316-319 (doi: 10.3923/ajps.2006.316.319).

72. Jami Al-Ahmadi M., Kafi M. Cardinal temperatures for germination of Kochia scoparia (L.). Journal of Arid Environments, 2007, 68(2): 308-314 (doi: 10.1016/j.jaridenv.2006.05.006).

73. Berti M.T., Johnson B.L. Seed germination response of cuphea to temperature. Industrial Crops and Products, 2008, 27(1): 17-21 (doi: 10.1016/j.indcrop.2007.05.004).

74. Tabrizi L., Nasiri M., Kouchaki A. Investigations on the cardinal temperatures for germination of Plantago ovata and Plantago psyllium. Iranian Journal of Field Crops Research, 2005, 2(2): 143150.

75. Bannayan M., Nadjafi F., Rastgoo M., Tabrizi L. Germination properties of some wild medicinal plants from Iran. Seed Technology, 2006, 28(1): 80-86. 